\title{
Effects of Merogel coverage on wound healing and ostial patency in endonasal endoscopic dacryocysto- rhinostomy for primary chronic dacryocystitis
}

${ }^{1}$ Department of Orbital and Oculoplasty Surgery, Eye Hospital of Wenzhou Medical College, Wenzhou, Zhejiang, PR China

${ }^{2}$ Discipline of Ophthalmology and Visual Sciences, University of Adelaide, and South Australian Institute of Ophthalmology, Adelaide, South Australia, Australia

Correspondence: W Wu, Department of Orbital and Oculoplasty Surgery,

Eye Hospital of Wenzhou Medical College, No. 270

Xueyuan Xi Road, Wenzhou City, Zhejiang 325027

PR China

Tel: + 86057788068958 ;

Fax: + 86057788832083

E-mail: wuwencan118@

163.com

Received: 13 April 2010 Accepted in revised form: 1 February 2011 Published online: 11 March 2011

\begin{abstract}
Purpose To investigate the effects of Merogel coverage on ostial patency in endonasal endoscopic dacryocystorhinostomy (EES-DCR) for primary chronic dacryocystitis (PCD).

Methods In all, 260 patients with unilateral PCD were randomized into two groups: the Merogel group and the control group. All patients underwent EES-DCR. The Merogel group received Merogel covering the wound 1-2 $\mathrm{mm}$ around the ostium and the control group received no treatment. Patients were followed up for 9 months. The mucosal epithelialization of the wound, the proliferation of fibrosis tissue, and the success rate of ostial patency were compared. Results Our study included 112 patients in the Merogel group and 115 patients in the control group. At the 2-week review, intact mucosal epithelium lined the ostia in 96 Merogel patients compared with 80 control patients (ITT analysis: $\chi^{2}=4.502, P=0.034$ ). At the 9-month review, scars were present in 18 patients in the Merogel group compared with 39 patients in the control group (ITT analysis: $\chi^{2}=9.909, P=0.002$, ITT analysis). No differences were observed in the granulation formation between the two groups. The success rate of ostial patency reached $94.6 \%$ (106/112) in the Merogel group compared with $80 \%(92 / 115)$ in the control group (ITT analysis: $\chi^{2}=4.151, P=0.042$ ).

Conclusion Merogel coverage may enhance the success rate of EES-DCR for PCD by
\end{abstract}

W Wu'1, PS Cannon², W Yan', Y Tu', D Selva² and $\mathrm{J} \mathrm{Qu}^{1}$ promoting mucosal epithelial healing and preventing excessive scarring.

Eye (2011) 25, 746-753; doi:10.1038/eye.2011.44; published online 11 March 2011

Keywords: endonasal endoscopic dacryocystorhinostomy; hyaluronan; ostial patency; mucosa epithelialization; primary chronic dacryocystitis

Introduction

Recently, the endonasal endoscopic approach for dacryocystorhinostomy (EES-DCR) has become increasingly popular over the external dacryocystorhinostomy (Ex-DCR) approach. The success rate for EES-DCR, however, varies markedly from 54 to $96 \% .{ }^{1-8}$ Numerous modifications have been developed to promote ostial patency, ranging from various methods of producing the nasal mucosal and/or lacrimal sac flaps, ${ }^{2,4,9-12}$ varying the size of the bony ostium, ${ }^{4,12-14}$ lacrimal sac incision, ${ }^{15}$ to stenting. ${ }^{16,17}$ Nevertheless, ostial closure or obstruction still occurs, mostly due to excessive scars/synechia or granulation formation at the ostium. ${ }^{3,5,6,8,9,18-20}$ Some authors advocate the use of mitomycin $\mathrm{C}$ (MMC) intraoperatively to reduce fibrosis formation, ${ }^{21-26}$ although granulation tissue has been reported to form around the ostia following MMC application during EES-DCR. ${ }^{27,28}$

Hyaluronan is a ubiquitous polysaccharide component of the extracellular matrix. Both hyaluronan and its derivatives have been 
reported to reduce scarring and to promote wound healing in naso-sinal surgery. ${ }^{29-31}$ Merogel (Medtronic Xomed, Jacksonville, FL, USA) is an esterified derivative of hyaluronan that appears to have a longer duration than hyaluronan and can be easily used in a non-woven sponge preparation. Merogel has been used as an antiadhesive packing agent with good effect to stimulate mucosal epithelial healing in functional endoscopic sinus surgery (FESS), ${ }^{29-31}$ middle ear surgery, ${ }^{32,33}$ and tympanic membrane perforation repair surgery. ${ }^{34}$ However, a number of studies have disputed the role of Merogel in mucosal epithelium recovery. ${ }^{35-38}$

Our study aimed to investigate whether Merogel coverage stimulates wound mucosal regeneration and its epithelialization around the ostia to improve long-term ostial patency in EES-DCR.

\section{Materials and methods}

This study was conducted at the Eye Hospital of Wenzhou Medical College between October 2006 and February 2010. Ethical approval was obtained from the Institutional Review Board and informed consent was obtained from all subjects, in accordance to the tenets of the declaration of Helsinki. The diagnosis of primary chronic dacryocystitis (PCD) was made on the basis of a history of epiphora with purulent discharge and regurgitation on nasolacrimal irrigation. All consecutive patients with unilateral PCD were included in the study. We excluded patients with acute dacryocystitis, a previous history of physical scars, previous lacrimal surgery, eyelid malposition including ectropion or entropion, and previous facial fractures or nasal diseases, such as polyps and chronic rhinosinusitis. Patients with isolated nasal septum deviation were not excluded. All patients underwent non-laser EES-DCR, which was performed by a single surgeon (WW). Before surgery, all patients were randomized by an independent member of the staff into two groups. The first group received Merogel at the end of the procedure, which covered the wound 1-2 $\mathrm{mm}$ around the ostium (the Merogel group), and the second group received nothing at the end of the routine EES-DCR (control group).

\section{Surgical technique of non-laser EES-DCR}

The non-laser EES-DCR was performed mainly as described by Tsirbas et $a l^{4,10}$ and $\mathrm{Wu}$ et al. ${ }^{39} \mathrm{~A}$ mixture of $2 \mathrm{ml}$ of $2 \%$ lidocaine and epinephrine (1:100000) was injected into the lateral nasal wall in addition to an external anterior ethmoidal nerve block and an infraorbital nerve block. Under direct visualization with a $45^{\circ}$ 4-mm endonasal endoscope (Karl Storz, Tuttlingen, Germany), the lateral nasal mucosa was incised in the area of the lacrimal sac fossa and removed. An osteotomy $\left(8 \mathrm{~mm} \times 10 \mathrm{~mm}\right.$ in size) was created using an angled $\left(15^{\circ}\right)$ coarse diamond burr attached to a microdebrider (XPS3000, Medtronic Xomed, Minneapolis, MN, USA) and/or a Hajek-Koffler forward-biting punch. Further, the lacrimal sac was tented using a probe through the superior canaliculus and incised vertically with a sickle knife to create a large posterior lacrimal sac flap. The flap was then flattened on the lateral nasal mucosal wall; this was the final step in the procedure for the control group. In the Merogel group, two pieces of Merogel were stretched to cover the flattened posterior lacrimal sac flap and the wound surface $1-2 \mathrm{~mm}$ around the ostium (Figures 1a and b).

\section{Postoperative care and follow-up}

All patients were hospitalized for the surgery and received oral antibiotics for 5-7 days. Patients were discharged on a monthly prescription of a topical mixture of antibiotic and steroid eye drops four times daily (Maxitrol, Alcon Laboratories, Fort Worth, TX, USA), and an intranasal steroid spray three times daily (Rhinocort Aqua, AstraZeneca, Wilmington, DE, USA). A nasal endoscopic examination was performed at day 3, following surgery on all patients with careful removal of blood clots/debris obstructing the ostial site. This was repeated every 2-3 days over the next 2 weeks. Followup reviews were weekly for 2 weeks, then monthly for 2 months, and finally every 2-3 months for the next 9 months. At each review, regular nasal endoscopic examinations were carried out to assess the wound healing, with specific reference to the status of epithelial mucosa and the presence of scars and granulation tissue within 1-2 $\mathrm{mm}$ of the ostium, as described by Berlucchi et al $^{29}$ and $\mathrm{Xu}$ et al.$^{30}$ Symptoms of epiphora and purulent discharge were recorded and nasolacrimal irrigation was performed by an independent member of the staff.

The patent ostium was defined as an ostium that was freely flowing with no regurgitation on nasolacrimal irrigation, and was lined by $1-2 \mathrm{~mm}$ of healthy epithelized mucosa. Successful outcome was defined subjectively and objectively by a patent ostium in the absence of epiphora and purulent discharge at the 9-month review.

\section{Statistical analyses}

Statistical analyses were performed with SPSS 13.0 software (SPSS Inc., Chicago, IL, USA). Group means of primary data of the patients were compared with an independent sample $t$-test. Success rates of the freely flowing lacrimal reconstruction, ostial patency, ostial epithelization, and ostial fibrosis at the 9-month review 

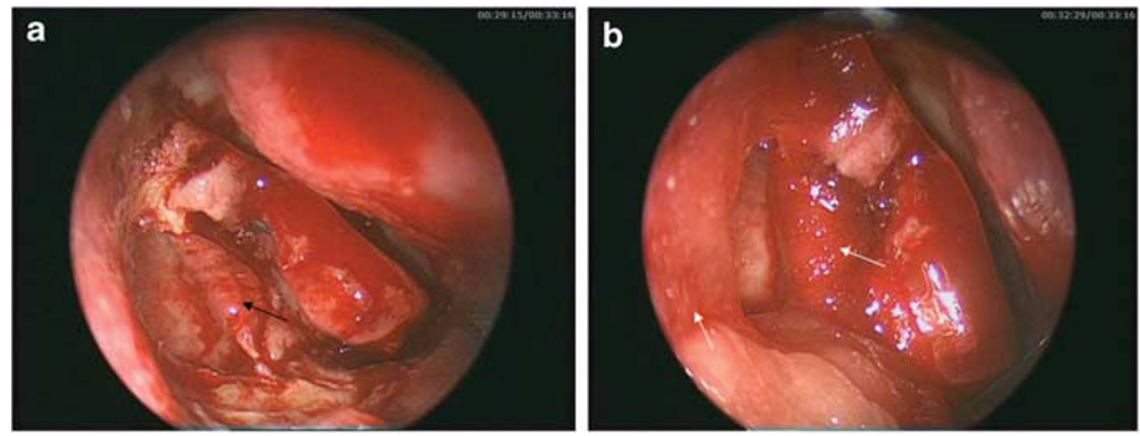

Figure 1 Application of Merogel during endonasal endoscopic dacryocystorhinostomy. (a) A clinical photograph of a C-shaped lacrimal flap (black arrow) that lies flattened over the lateral nasal wall, following removal of the nasal mucosal flap. (b) A clinical photograph of the Merogel (white arrow) covering the ostial surface.

were evaluated with Pearson's $\chi^{2}$-test. $P<0.05$ was considered as statistically significant in all tests.

\section{Results}

We randomly assigned 260 patients with unilateral PCD into two groups. In all, 18 patients in the Merogel group were excluded for the following reasons: 11 patients had no Merogel present over the ostial site at the first week of surgery, as detected by the first and second endonasal examination and 7 patients failed to complete the follow-up. In all, 15 patients in the control group were excluded, 3 patients had complicated heavy nasal bleeding within the first week following surgery, and 12 patients failed to complete the follow-up. Therefore, we included 112 patients in the Merogel group and 115 patients in the control group. There were no significant differences between the groups for patient age, gender, and history of symptoms (Table 1). In all, 13 patients in the Merogel group underwent nasal septoplasty compared with 17 patients in the control group for significant septal deviation.

We found that the Merogel was mostly absorbed within 2 weeks following surgery (Figures $2 a$ and $b$ ). At the 2-week review, all ostia remained patent for both groups. We found that 96 patients (85.7\%) in the Merogel group had a healed ostium with a lining of intact epithelial mucosa compared with 80 patients (69.6\%) in the control group (PP analysis: $\chi^{2}=8.495$, $P=0.004$; ITT analysis: $\chi^{2}=4.502, P=0.034$; Table 2). At the 9-month review, healthy epithelial mucosa lined the ostia in 94 patients (83.9\%) in the Merogel group (Figure 2c) and in 76 patients (66.1\%) in the control group (PP analysis: $\chi^{2}=9.605, P=0.002$; ITT analysis: $\chi^{2}=9.909$, $P=0.002$ ). The success rate of ostial patency was $93.4 \%$ $(106 / 112)$ in the Merogel group and 82.6\% (92/115) in the control group (PP analysis: $\chi^{2}=10.918, P=0.001$; ITT analysis: $\chi^{2}=4.151, P=0.042$ ). This was consistent with
Table 1 Demographic data of patients from both groups

\begin{tabular}{lcccrr}
\hline Characteristics & Merogel group & Control group & $\mathrm{t}$ & $\chi^{2}$ & $\mathrm{P}$ \\
\hline Number & 112 & 115 & & \\
Age (years) & $41.8 \pm 13.6$ & $40.4 \pm 12.9$ & 0.801 & 0.424 \\
Gender (M/F) & $27 / 85$ & $32 / 83$ & \multicolumn{4}{c}{0.408} & 0.523 \\
Eye sides (R/L) & $69 / 43$ & $75 / 37$ & \multicolumn{4}{c}{0.700} & 0.403 \\
History (years) & $4.1 \pm 3.1$ & $4.5 \pm 3.0$ & -0.985 & 0.339 \\
\hline
\end{tabular}

Abbreviations: F, female; L, left; $\mathrm{M}$, male; R, right.

the results of free-flowing lacrimal reconstruction (Table 2).

Table 3 compares the scarring and the granulation formation between the two groups. At the 9-month review, scars were present in 18 Merogel patients compared with 39 control patients (PP analysis: $\chi^{2}=9.605, P=0.002$; ITT analysis: $\chi^{2}=9.909, P=0.002$ ). We observed no significant difference in granulation formation between the two groups.

Four patients had a failed outcome compared with 21 control patients ( $P=0.043$; Figures $3 \mathrm{a}$ and $\mathrm{b}$ ). Granulation tissue resulting in partial/complete ostial obstruction occurred in four of those failures, two patients from each group ( $P=0.565$; Figures $3 c$ and d; Table 3 ). The remaining failed patients did not have visible ostial closure/stenosis, but had variable degrees of fibrosis proliferation present within $1-2 \mathrm{~mm}$ of the ostia; Figures 4a-d).

\section{Discussion}

Silicone stenting ${ }^{16,17}$ and the application of mitomycin $\mathrm{C}^{21-26}$ are the most commonly used methods to maintain ostial patency in EES-DCR surgery. However, limitations have been reported for both of them, including the potential of silicone intubation to induce an 

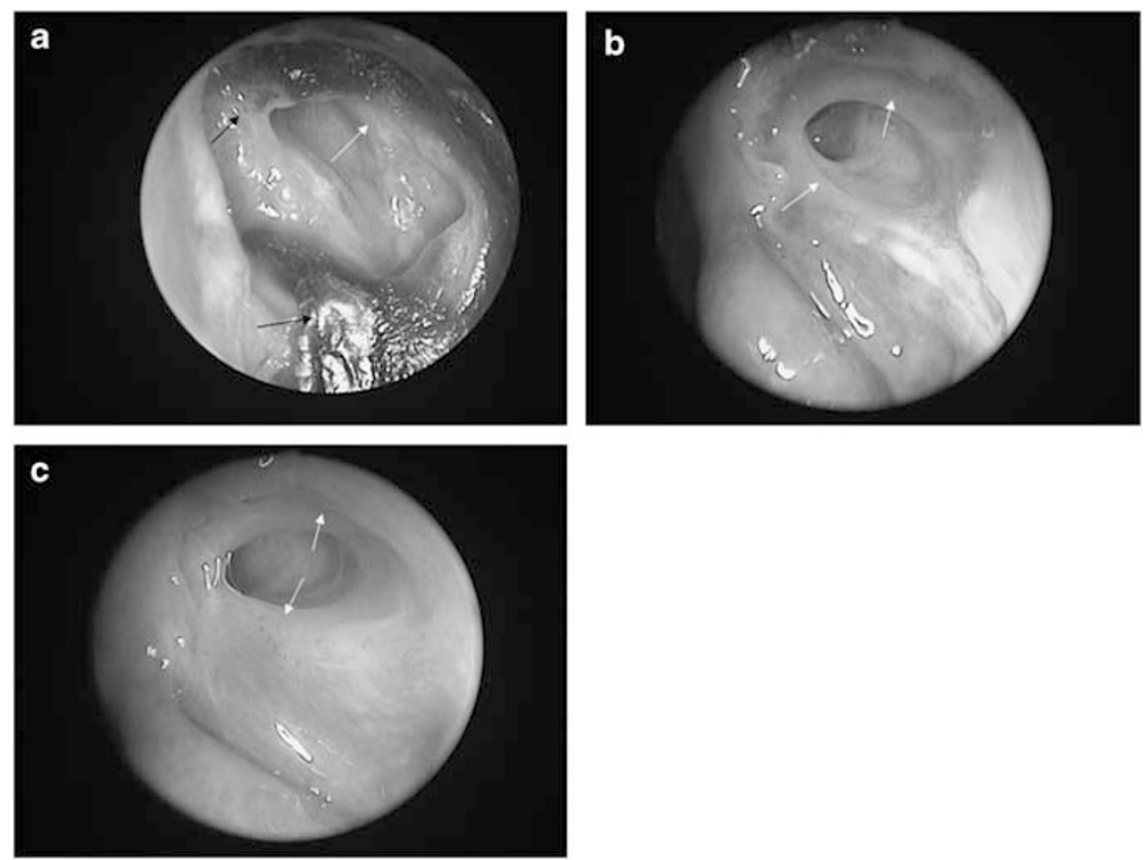

Figure 2 Wound healing and regeneration of the ostial mucosal epithelium following surgery, as observed by nasal endoscopy in a single patient from the Merogel group. (a) A clinical photograph at the 6-day review illustrating some residual Merogel (black arrows) covering the wound surface and intact mucosal epithelium (white arrow) around the patent ostium. (b) A clinical photograph taken at 12 days, demonstrating that the Merogel has been absorbed and that the ostium is patent with intact mucosal epithelium (white arrow). (c) A clinical photograph showing a patent ostium lined by healthy epithelium (white arrow) at 9 months.

Table 2 Rates (\%) of ostial epithelium epithelialization and ostial patency in both groups

\begin{tabular}{|c|c|c|c|c|c|c|}
\hline & Merogel group & Control group & $\chi^{2}$-test ${ }^{\mathrm{a}}$ & $\mathrm{P}^{\mathrm{a}}$ & $\chi^{2}$-test ${ }^{\mathrm{b}}$ & $\mathrm{P}^{\mathrm{b}}$ \\
\hline OER (at 2 weeks review) & $85.7 \%(96 / 112)$ & $69.6 \%(80 / 115)$ & 8.495 & 0.004 & 4.502 & 0.034 \\
\hline OER (at 9 months review) & $83.9 \%(94 / 112)$ & $66.1 \%(76 / 115)$ & 9.605 & 0.002 & 9.909 & 0.002 \\
\hline OP (at 9 months review; \%) & $94.6 \%(106 / 112)$ & $80.0 \%(92 / 115)$ & 10.918 & 0.001 & 4.151 & 0.042 \\
\hline
\end{tabular}

Abbreviations: OER, ostial epithelial regeneration (viewed by endoscopy); OP, ostial patency.

${ }^{\text {a }} P$-value was evaluated by Pearson's $\chi^{2}$-test according to per-protocol analysis.

${ }^{\mathrm{b}} P$-value was evaluated by Pearson's $\chi^{2}$-test corrected by intention to treat analysis.

Table 3 Rates of scarring, granulation formation, and failure of ostial patency in both groups

\begin{tabular}{|c|c|c|c|c|c|}
\hline \multirow[t]{2}{*}{ Group } & \multirow[t]{2}{*}{ Total number } & \multicolumn{2}{|c|}{ Scar formation } & \multicolumn{2}{|c|}{ Granulation formation } \\
\hline & & Number & Failure & Number & Failure \\
\hline Merogel group & 112 & $16.1 \%(18 / 112)$ & $22.2 \%(4 / 18)$ & $6.3 \%(7 / 112)$ & $28.6 \%(2 / 7)$ \\
\hline Control group & 115 & $33.9 \%(39 / 115)$ & $53.8 \%(21 / 39)$ & $13.0 \%(15 / 115)$ & $13.3 \%(2 / 15)$ \\
\hline$\chi^{2}$-test $^{\mathrm{a}}$ & & 9.605 & & 2.992 & \\
\hline$P^{\mathrm{b}}$ & & 0.002 & 0.043 & 0.084 & 0.565 \\
\hline$\chi^{2}$-test $^{\mathrm{c}}$ & & 9.909 & & 3.178 & \\
\hline$P^{c}$ & & 0.002 & & 0.075 & \\
\hline
\end{tabular}

a $P$-values of the rates of scar and granulation formation were evaluated by Pearson's $\chi^{2}$-test according to per-protocol analysis.

${ }^{\mathrm{b}} P$-values of the rates of failure resulted from the scar and granulation formation were evaluated by Fisher's exact test.

' $P$-value was evaluated by Pearson's $\chi^{2}$-test corrected by intention to treat analysis.

inflammatory response with ostial scarring ${ }^{18-20}$ and the inhibitory effect of MMC on fibroblasts, which potentially limits the regeneration of healthy epithelium. ${ }^{27,28}$ Therefore, the ideal agent should promote healthy re-epithelialization without excessive scarring, to ensure ostial patency in DCR. 

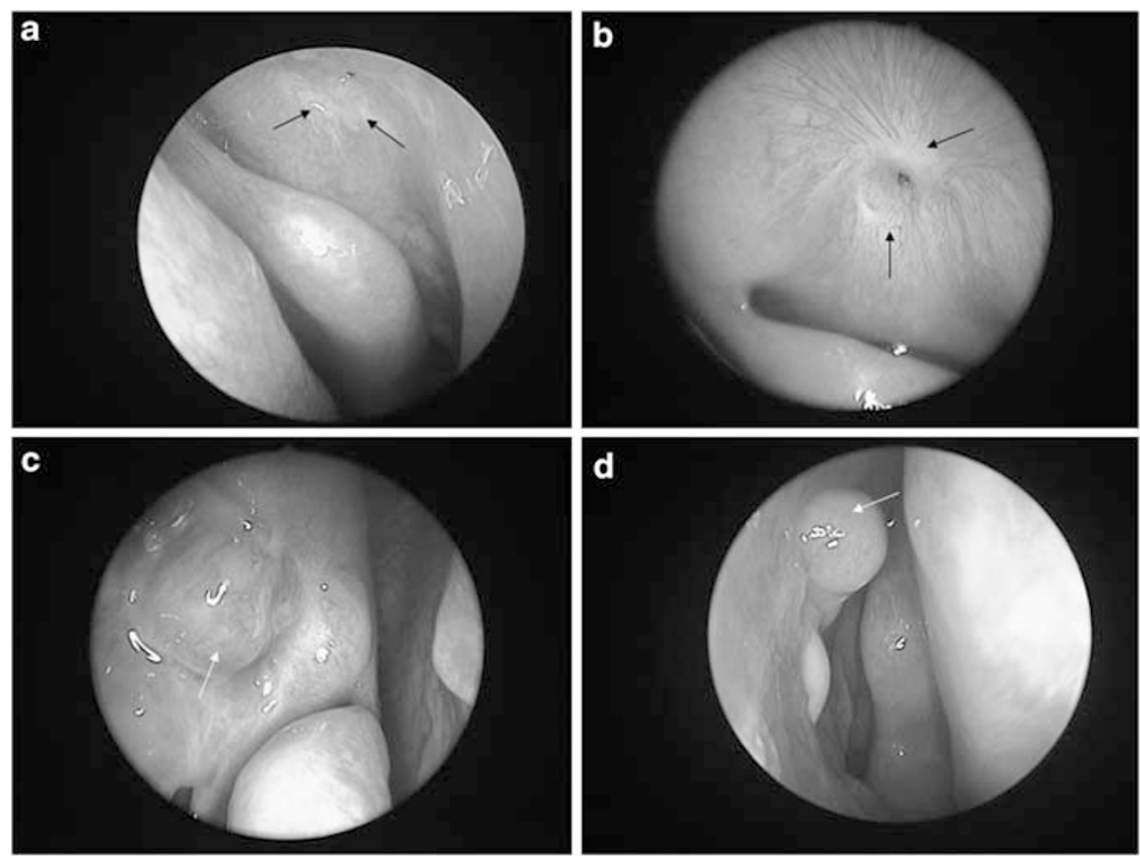

Figure 3 Examples of ostial closure and surgical failure secondary to excessive scarring (black arrow) and/or granulation formation (white arrow) as observed by nasal endoscopy at 9 months. (a) A clinical photograph of extensive scarring (black arrows) resulting in ostial stenosis in a Merogel patient. (b) A clinical photograph showing scarring and ostial stenosis in a control patient. (c) A clinical photograph illustrating a large granuloma obstructing the ostium in a Merogel patient. (d) A clinical photograph demonstrating ostial obstruction secondary to a granuloma in a control patient.
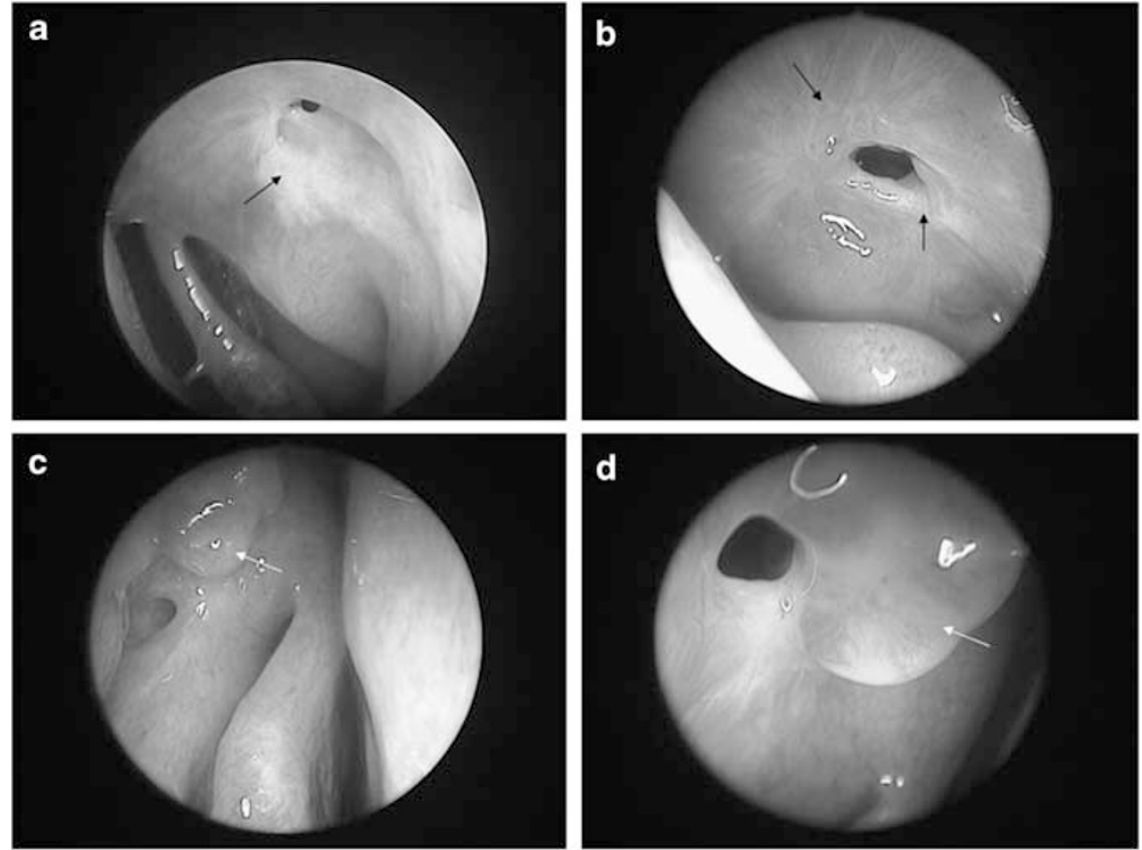

Figure 4 Examples of ostial patency in the presence of scarring (black arrow) and/or granulation tissue (white arrow) as observed by nasal endoscopy at 9 months. (a) A clinical photograph of a patent ostium with surrounding scar tissue in a Merogel patient. (b) A clinical photograph demonstrating a patent ostium with scar tissue in a control patient. (c) A clinical photograph illustrating granulation tissue adjacent to a patent ostium in a Merogel patient. (d) A clinical photograph in a control patient showing a patent ostium in the presence of an extensive granuloma. 
Our study showed that, at the 2-week review, $85.7 \%$ of the patients (96/112) in the Merogel group had epithelial mucosa lining the ostia, which was higher than that in the control group $(69.6 \%, 80 / 115)$. At the 9-month review, the success rate of ostial patency reached $93.4 \%(106 / 112)$ in the Merogel group, as opposed to the control group $(82.6 \%, 92 / 115)$. We observed that the rate of scar formation was lower in the Merogel group, with a lower incidence of ostial failure than in the control group. These results suggest that Merogel coverage can significantly improve the success rate of ostial patency for EES-DCR by stimulating wound healing and mucosa epithelialization and by preventing the formation of fibrotic tissue around the ostia. This is consistent with previous studies. ${ }^{29-31}$ Berlucchi et al ${ }^{29}$ found that the patients packed with Merogel had less nasal adhesions at both 4 and 12 weeks, compared with the traditional non-resorbable packs during FESS. They also reported an improvement in re-epithelialization with reduced granulation tissue in the Merogel group, which was supported by Xu et al. ${ }^{30}$ However, Wormald et al ${ }^{36}$ and Miller et $a l^{38}$ reported that Merogel packing did not alter the healing, edema, or synechiae formation after FESS.

Proctor et $a l^{35}$ and Maccabee $e t l^{37}$ suggested that Merogel tended to increase reactive fibrosis and impair mucosal healing when used as a packing agent in rabbit maxillary sinus wounds. We propose that these limited effects observed with Merogel may be explained by the large mucosal areas denuded during their procedure and that the mechanisms of wound healing and mucosa epithelialization is different between FESS for chronic rhinosinusitis and EES-DCR without rhinosinusitis.

Traditionally, it was critical during EES-DCR to create one nasal sac flap and one lacrimal sac flap and to appose them closely. 2,8,9-11,14 Our technique involves removal of the nasal mucosa flap and the creation of a large C-shaped lacrimal sac flap that is laid flat posteriorly to cover the lateral nasal mucosal wall, as described by $\mathrm{Wu}$ et al. ${ }^{39}$ We appose the lacrimal sac flap border with the nasal mucosal wall. At the 2-week review, we observed that more patients in the Merogel group had healthy epithelial-lined ostia, especially in the areas between the lacrimal sac and the lateral nasal mucosa wall, than the control group. This suggests that Merogel has a role in promoting mucosal epithelial regeneration, which we consider a key factor for maintaining ostial patency. It also offers additional benefit as a physical packing material in maintaining opposition of the flaps. This was particularly apparent in patients with small lacrimal sacs, at which the creation of a large posterior lacrimal flap was difficult.

Our study has demonstrated that adjunctive use of Merogel may enhance the success outcomes in EES-DCR for PCD. The mechanisms for this enhancement may include the following: (1) Merogel helps promotion of early re-epithelialization of the ostium; (2) it inhibits the fibrotic tissues at the ostium; and (3) it serves as a physical packing barrier for apposition of lacrimal sac and nasal mucosa flaps.

\section{Summary}

What was known before

- Though numerous modifications, including surgical techniques, silicone intubation, and intraoperative application of mitomycin C, have been used to promote success rate of endonasal endoscopic dacryocystorhinostomy (EES-DCR), some patients have still failed in ostial patency because of ostial stenosis or closure resulted from excessive scars and/or granulation tissue formation.

What this study adds

- Our study has demonstrated that adjunctive use of Merogel can significantly improve the success rate of ostial patency for EES-DCR by stimulating wound healing and mucosa epithelialization and by preventing the formation of fibrotic tissue around the ostia.

\section{Conflict of interest}

The authors declare no conflict of interest.

\section{Acknowledgements}

We are grateful to Mr Alan Hoare, a Clinical Photographer at South Australian Institute of Ophthalmology, for his assistance in formatting the clinical images. Thanks to professor Xinjun Yang, a statistician in the Department of Public Health of Wenzhou Medical College, for reviewing and adjusting the statistical analysis of this paper.

\section{Author contributions}

WW designed the study; WW, WY, and YT analyzed and interpreted the data; WW, WY, and YT collected the data; WW, PSC, DS, and JQ drafted the manuscript; and JQ gave the final approval.

\section{References}

1 Zenk J, Karatzanis AD, Psychogios G, Franzke K, Koch M, Hornung $\mathrm{J}$ et al. Long-term results of endonasal dacryocystorhinostomy. Eur Arch Otorhinolaryngol 2009; 26: $1733-1738$. 
2 Sonkhya N, Mishra P. Endoscopic transnasal dacryocystorhinostomy with nasal mucosal and posterior lacrimal sac flap. J Laryngol Otol 2009; 123: 320-326.

3 Ben Simon GJ, Joseph J, Lee S, Schwarcz RM, McCann JD, Goldberg RA. External versus endoscopic dacryocystorhinostomy for acquired nasolacrimal duct obstruction in a tertiary referral center. Ophthalmology 2005; 112: $1463-1468$.

4 Tsirbas A, Davis G, Wormald PJ. Mechanical endonasal dacryocystorhinostomy versus external dacryocystorhinostomy. Ophthal Plast Reconstr Surg 2004; 20: $50-56$.

5 Onerci M, Orhan M, Ogretmenoğlu O, Irkeç M. Long-term results and reasons for failure of intranasal endoscopic dacryocystorhinostomy. Acta Otolaryngol 2000; 120: 319-322.

6 Hartikainen J, Antila J, Varpula M, Puukka P, Seppä H, Grénman R. Prospective randomized comparison of endonasal endoscopic dacryocystorhinostomy and external dacryocystorhinostomy. Laryngoscope 1998; 108: 1861-1866.

7 Yung MW, Hardman-Lea S. Endoscopic inferior dacryocystorhinostomy. Clin Otolaryngol Allied Sci 1998; 23: 152-157.

8 Sprekelsen MB, Barberán MT. Endoscopic dacryocystorhinostomy: surgical technique and results. Laryngoscope 1996; 106: 187-189.

9 Trimarchi M, Giordano Resti A, Bellini C, Forti M, Bussi M. Anastomosis of nasal mucosal and lacrimal sac flaps in endoscopic dacryocystorhinostomy. Eur Arch Otorhinolaryngol 2009; 266: 1747-1752.

10 Tsirbas A, Wormald PJ. Endonasal dacryocystorhinostomy with mucosal flaps. Am J Ophthalmol 2003; 135: 76-83.

11 Mahendran S, Stevens-King A, Yung MW. How we do it: the viability of free mucosal grafts on exposed bone in lacrimal surgery-a prospective study. Clin Otolaryngol 2006; 31: 324-327.

12 Yuen KS, Lam LY, Tse MW, Chan DD, Wong BW, Chan WM. Modified endoscopic dacryocystorhinostomy with posterior lacrimal sac flap for nasolacrimal duct obstruction. Hong Kong Med J 2004; 10: 394-400.

13 Mann BS, Wormald PJ. Endoscopic assessment of the dacryocystorhinostomy ostium after endoscopic surgery. Laryngoscope 2006; 116: 1172-1174.

14 Wormald PJ. Powered endoscopic dacryocystorhinostomy. Laryngoscope 2002; 112: 69-72.

15 Sham CL, van Hasselt CA. Endoscopic terminal dacryocystorhinostomy. Laryngoscope 2000; 110: 1045-1049.

16 Apaydin KC, Fisenk F, Karayalcin B, Akar Y, Saka O. Endoscopic transnasal dacryocystorhinostomy and bicanalicular silicone tube intubation. Ophthalmologica 2004; 218: 306-311.

17 Tabatabaie SZ, Heirati A, Rajabi MT, Kasaee A. Silicone intubation with intraoperative mitomycin $C$ for nasolacrimal duct obstruction in adults: a prospective, randomized, double-masked study. Ophthal Plast Reconstr Surg 2007; 23: 455-458.

18 Unlu HH, Gunhan K, Baser EF, Songu M. Long-term results in endoscopic dacryocystorhinostomy: is intubation really required? Otolaryngol Head Neck Surg 2009; 140: 589-595.

19 Smirnov G, Tuomilehto H, Teräsvirta M, Teräsvirta M, Nuutinen J, Seppä J. Silicone tubing is not necessary after primary endoscopic dacryocystorhinostomy: a prospective randomized study. Am J Rhinol 2008; 22: 214-217.
20 Oztürk S, Konuk O, Ilgit ET, Unal M, Erdem O. Outcome of patients with nasolacrimal polyurethane stent implantation: do they keep tearing? Ophthal Plast Reconstr Surg 2004; 20(2): 130-135.

21 Dolmetsch AM, Gallon MA, Holds JB. Nonlaser endoscopic endonasal dacryocystorhinostomy with adjunctive mitomycin C in children. Ophthal Plast Reconstr Surg 2008; 24: 390-393.

22 Selig YK, Biesman BS, Rebeiz EE. Topical application of mitomycin-C in endoscopic dacryocystorhinostomy. Am J Rhinol 2000; 14: 205-207.

23 Camara JG, Bengzon AU, Henson RD. The safety and efficacy of mitomycin $\mathrm{C}$ in endonasal endoscopic laserassisted dacryocystorhinostomy. Ophthal Plast Reconstr Surg 2000; 16: 114-118.

24 Zilelioğlu G, Uğurbaş SH, Anadolu Y, Akiner M, Aktürk T. Adjunctive use of mitomycin $\mathrm{C}$ on endoscopic lacrimal surgery. Br J Ophthalmol 1998; 82: 63-66.

25 Ugurbas SH, Zilelioglu G, Sargon MF, Anadolu Y, Akiner M, Aktürk T. Histopathologic effects of mitomycin-C on endoscopic transnasal dacryocystorhinostomy. Ophthalmic Surg Lasers 1997; 28: 300-304.

26 Deka A, Bhattacharjee K, Bhuyan SK, Barua CK, Bhattacharjee H, Khaund G. Effect of mitomycin C on ostium in dacryocystorhinostomy. Clin Experiment Ophthalmol 2006; 34: 557-561.

27 Roozitalab MH, Amirahmadi M, Namazi MR. Results of the application of intraoperative mitomycin $\mathrm{C}$ in dacryocystorhinostomy. Eur J Ophthalmol 2004; 14: 461-463.

28 Liu D, Bosley TM. Silicone nasolacrimal intubation with mitomycin-C: a prospective, randomized, double-masked study. Ophthalmology 2003; 110: 306-310.

29 Berlucchi M, Castelnuovo P, Vincenzi A, Morra B, Pasquini E. Endoscopic outcomes of resorbable nasal packing after functional endoscopic sinus surgery: a multicenter prospective randomized controlled study. Eur Arch Otorhinolaryngol 2009; 266: 839-845.

30 Xu G, Chen HX, Wen WP, Shi JB, Li Y. Clinical evaluation of local application of Merogel after endoscopic sinus surgery. Zhonghua Er Bi Yan Hou Ke Za Zhi 2003; 38: 95-97.

31 Soldati D, Rahm F, Pasche P. Mucosal wound healing after nasal surgery. A controlled clinical trial on the efficacy of hyaluronic acid containing cream. Drugs Exp Clin Res 1999; 25: 253-261.

32 Li G, Feghali JG, Dinces E, McElveen J, van de Water TR. Evaluation of esterified hyaluronic acid as middle ear-packing material. Arch Otolaryngol Head Neck Surg 2001; 127: 534-539.

33 Jang $\mathrm{CH}$, Park $\mathrm{H}$, Cho $\mathrm{YB}, \mathrm{Choi} \mathrm{CH}$. The effect of antiadhesive packing agents in the middle ear of guinea pig. Int J Pediatr Otorhinolaryngol 2008; 72: 1603-1608.

34 Ozturk K, Yaman H, Cihat Avunduk M, Arbag H, Keles B, Uyar Y. Effectiveness of MeroGel hyaluronic acid on tympanic membrane perforations. Acta Otolaryngol 2006; 126: $1158-1163$.

35 Proctor M, Proctor K, Shu XZ, McGill LD, Prestwich GD, Orlandi RR. Composition of hyaluronan affects wound healing in the rabbit maxillary sinus. Am J Rhinol 2006; 20: 206-211.

36 Wormald PJ, Boustred RN, Le T, Hawke L, Sacks R. A prospective single-blind randomized controlled study of use of hyaluronic acid nasal packs in patients after endoscopic sinus surgery. Am J Rhinol 2006; 20: 7-10. 
37 Maccabee MS, Trune DR, Hwang PH. Effects of topically applied biomaterials on paranasal sinus mucosal healing. Am J Rhinol 2003; 17: 203-207.

38 Miller RS, Steward DL, Tami TA, Sillars MJ, Seiden AM, Shete $\mathrm{M}$ et al. The clinical effects of hyaluronic acid ester nasal dressing (Merogel) on intranasal wound healing after functional endoscopic sinus surgery. Otolaryngol Head Neck Surg 2003; 128: 862-869.

39 Wu W, Yan W, MacCallum JK, Tu Y, Jiang AC, Yang Y et al. Primary treatment of acute dacryocystitis by endoscopic dacryocystorhinostomy with silicone intubation guided by a soft probe. Ophthalmology 2009; 116: $116-122$. 